\title{
A importância da confiança interpessoal para a consolidação do Programa de Saúde da Família
}

\author{
The importance of interpersonal trust \\ for the consolidation of Brazil's Family Health Program
}

Igor Vinicius Lima Valentim ${ }^{1}$

Alexandra Jochims Kruel ${ }^{1}$

${ }^{1}$ Escola deAdministração da Universidade Federal do Rio Grande do Sul - EA/ UFRGS RuaWashington Luis 855, Centro. 90010 460 Porto Alegre RS. valentim@gmail.com

\begin{abstract}
Brazil is characterized by significant social and economic discrepancies. Although guaranteed by the Brazilian Constitution as a universal social right, healthcare is a major challenge for the State, constituting one of the cruel est types of inequality in Brazil. Designed to even out these inequalities, Brazil's National Health System (SUS) is ruled by principles that include universal access and all-round care. Developed by the Brazilian Government as a tool for imple menting these principles, the Family $\mathrm{H}$ ealth Program is a management strategy for its $\mathrm{N}$ ational Health Policy. This paper analyzes the importance of trust between the main players in this Program as a crucial factor for its consolidation as a strategy for reorganizing this system. Theoretical input on trust and Government health policies served as the basis for this analysis, built up by the network of relationships among those most deeply engaged with this Program. After examining the many different relationships among the players, we conclude that trust is significant and relevant for all of them but, more particularly for the Community Health Agents who form the main links between the assisted population and other players in this process.

Key words Health, Government policies, Trust, Family $\mathrm{H}$ ealth Program
\end{abstract}

Resumo Vive-seem um país cuja realidadeaponta significativas discrepâncias socioeconômicas. A saúde, direito social universal garantido pela Constituição Federal, seconstitui em um dos princi pais desafios do Estado eem uma das mais cruéis desigualdades no Brasil. Visando também a redução das mesmas, a gestão do Sistema Único de Saúde regra-se por princípios como a universalidade de acesso e a integralidade da atenção. 0 Programa de Saúde da Família (PSF), desenvolvido pelo Governo Federal como uma ferramenta para alcançar estes princípios, é caracterizado como estratégia de gestão da política nacional de saúde. Este artigo tem como objetivo analisar a importância da confiança, entre os principais atores ativos do PSF, para sua consolidação como estratégia de reordenamento do sistema. U tilizouse aporte teórico sobre confiança e políticas públicas de saúde do governo, o qual se constituiu em base para a análise, desenvolvida a partir da teia de relacionamentos existentes entre os principais envolvidos no PSF. A pós o estudo das relações entre seus personagens, concluiu-se que a confiança possui importância ímpar em todas mas, principalmente, sobre a figura do Agente Comunitário deSaúde, o qual se constitui no principal elo de ligação entre a população atendida e os demais atores do processo.

Palavras-chave Saúde, Políticas públicas, Confiança, Programa Saúde da Família 


\section{Introdução}

0 processo de redemocratização do Brasil trouxe, junto com a 'Constituição Cidadã', de 1988, um novo sistema de atenção à saúde, no qual 0 Estado configurava-se como responsável por sua execução e qualquer cidadão brasileiro teria direito deacesso aos serviços eações desaúde. 0 já denominado Sistema Ú nico de Saúde (SUS) foi formalizado pela Constituição, na qual foram definidos princípios, diretrizes, características e organização do mesmo, melhor detalhados posteriormente na Lei Orgânica de Saúde.

A própria Constituição Federal de 1988 já exigia uma mudança contundente no modelo de atenção à saúde até então em vigência. Do modelo centralizado na medicalização, nos hospitais e no caráter curativo, passaria-se a um modelo voltado para as ações de prevenção e de promoção da saúde, baseado em atividades principalmentecoletivas.

Do homem individual, passou-se à visão do homem integral, membro de uma família e de uma comunidade, além de possuidor de uma história de vida e de saúde. M as, se por um lado, o discurso versa a respeito da vida em comunidades e do trabal ho em equipe, por outro, percebe-se que as relações sociais são cada vez mais dominadas pela competição e pelo excesso de individualismo.

Já no espectro do SUS, surgem dois programas: o Programa de Agentes Comunitários de Saúde (PACS) e o Programa de Saúde da Família (PSF), os quais se tornaram a base para a estratégia de Saúde da Família. Ambos os programas são baseados em pressupostos que defendem e necessitam da cooperação edo trabal ho em equipe. Entretanto, não é uma tarefa simples que pessoas com histórias de vida diferentes e possuidoras de objetivos e personalidades distintas trabaIhem em conjunto em função de um objetivo estipulado. Embora colegas de trabalho possam ser pressionados a cooperar, deve existir uma disposição voluntária por parte dos indivíduos para que o relacionamento atinja da melhor maneira possível os resultados desejados.

Esperar que os integrantes de um grupo cooperem voluntariamente é uma tarefa especialmente difícil, quando, como supramencionado, o homem em sociedade torna-se cada vez mais competitivo eindividualista. Desta forma, a confiança entre as pessoas é um dos itens de maior influência sobre as relações entre elas e, conseqüentemente, sobre o resultado do trabal ho em coletividade.
D eseja-se, neste artigo, investigar teoricamente em que medida a existência da confiança nas relações entre os envolvidos é importante para o êxito e a consolidação de uma estratégia de gestão da política pública de saúde nacional. Para tanto, utiliza-se o caso do PSF, estratégia que tem, como uma de suas bases, visitas domiciliares às casas da população atendida, e como um grande objetivo a promoção da saúde dos cidadãos brasileiros.

\section{Confiança}

A confiança permeia a vida de um indivíduo em diversos momentos e relações, com conseqüências que afetam, de maneira importante, tanto a sua trajetória, quanto a daqueles com os quais interage ${ }^{1}$. Desdesua raiz etimológica, seu significado remete ao credo em algo ou em alguém.

A confiança éconsiderada a base de qualquer relacionamento afetivo, sendo um fator de relevância para o sucesso ou insucesso de diversas relações. $\mathrm{Na}$ vida em sociedade, a confiança no poder público, no sistema monetário, enas instituições de uma maneira geral, se mostra necessária, inclusive, para a manutenção da ordem ${ }^{1}$.

Quando 0 assunto é trabalho, tanto a confiança entre os colegas quanto aquela entre indivíduos e organizações irão trazer significativos impactos para a maneira como a pessoa se relaciona, produz ecomo épercebida pelas demais, aportando conseqüências, também, para a organização ${ }^{2,3}$. Conseqüentemente, entende-se 0 motivo da confiança se en contrar, cada vez mais, no centro das atenções quando 0 assunto é a teorização sobre as sociedades contemporâneas ${ }^{1,4}$.

Partindo-se do princípio que, então, a confiança é importante para as relações sociais, ela é encarada ${ }^{4}$ como uma maneira de reduzir a complexidade, já que nem sempre existem alternativas para uma pessoa, que não a de confiar. Fazse necessário entender, afinal, quais os componentes do construto confiança.

A decisão de confiar ou não em al guém é influenciada por um componente constituído pelo julgamento racional do indivíduo, com base no que ele julga "boas razões" 1,5 . Porém, para que esta avaliação possa ser realizada, é importante que esta pessoa disponha de uma base de informações. Esta base, tratada como familiaridade ${ }^{4}$, é formada pelo conhecimento prévio do observado, engloba as experiências anteriores e as informaç̃os a respeito do mesmo, constituindo elementos de uma dimensão cognitiva do cons- 
truto ${ }^{1}$. Estas informações a respeito do observado podem incluir a identificação de valores ${ }^{2}$ os quais o observador considera como característicos de uma pessoa confiável, como o respeito ou a honestidade.

As ditas "boas razões" não se constituem em motivo suficiente para que uma pessoa confie em outra. Ainda dentro deuma dimensão cognitiva ${ }^{1}$, a confiança éinfluenciada também pela realidade coletiva cognitiva ${ }^{4}$, ou seja, a percepção por parte do observador de que as demais pessoas também consideram o observado como confiável. Quando uma pessoa acredita que as outras não confiam no observado, o processo de construção da confiança pode ser dificultado4.

Assumir que a confiança é constituída apenas por elementos cognitivos se mostra demasiadamente ingênuo. As emoções e sentimentos existentes entreas pessoas se constituem em parte importante das relações entre elas e, conseqüentemente, influem diretamente na construção da confiança, visto que investimentos emocionais são feitos por ambas as partes ${ }^{1}$. Esta dimensão emocional da confiança contribui, segundo os autores, para a base da dimensão cognitiva, a partir do conhecimento que uma quebra da relação de confiança ameaça trazer sofrimento emocional para os envolvidos na relação, inclusive para o traidor.

U ma das principais ameaças às relações de confiança é 0 'segredo sistemático' ${ }^{6}$, ou seja, a proposital sonegação de informações entre os envolvidos - um comportamento oposto à transparência.

Também se constitui em um elemento influenciador da confiança nas relações interpessoais a 'confiança personalizada'7. Ela é caracterizada como a propensão do observado em, usualmente, confiar em outras pessoas, englobando suas expectativas, características pessoais e el ementos nos quais costuma confiar.

Em adição à dimensão cognitiva e à emocional, a confiança também possui aspectos relacionados ao comportamento dos indivíduos ${ }^{1}$. Ou seja, a decisão de confiar em alguém é baseada também na observação do comportamento alheio. Por um lado, o observador analisa se 0 comportamento do observado demonstra que ele é confiável ${ }^{1,6}$. Por outro lado, 0 observador também percebe se o observado parece confiar nele - guardando uma relação estreita com a reciprocidade: na medida em que o observador percebequeo observado parececonfiar nele, tende a reciprocamente ter uma maior propensão a confiar no observado4.
Um outro componenteimportanteda dimensão comportamental da confiança é a representação ${ }^{4,8}$, ou seja, um comportamento proposital por parte do observado, com o intuito de parecer ser confiável para o observador, pode influenciar sua opinião se este observador considerar como verdadeiro - enão como uma representação - aquele comportamento "forjado".

As dimensões da confiança tratadas nestetrabalho não devem ser consideradas de maneira isolada, visto que uma serve de suporte para a outra, estando intimamente ligadas.

Como abordado anteriormente, a confiança entre os colegas de trabal ho traz impactos significativos para o resultado do mesmo. Quando o trabal ho realizado envolve aspectos de importância extrema, como a saúde dos cidadãos, a responsabilidade do resultado aumenta ainda mais, exigindo a maior dedicação possível por parte dos envolvidos. Neste caso, a cooperação entre os indivíduos em prol de um objetivo comum ganha destaque.

A confiança e a cooperação estão ligadas, em parte, com o prazer no trabalho e, sem a primeira, não pode existir nem cooperação nem coletividade no trabalho $0^{6}$. Porém, Gambetta ${ }^{9}$ considera que a confiança não é pré-condição para a cooperação, sendo um resultado dela, construída e fortalecida ao longo das experiências.

Para os fins destetrabalho, considera-se que, se por um lado, é possível trabalhar e cooperar com pessoas nas quais não se confia, o trabal ho tende ser a muito mais frutífero quando existe confiança entre os indivíduos 2, 3, 9, 10.

\section{Políticas públicas de saúde no Brasil - o Sistema Único de Saúde}

A partir de 1988, com a promulgação da Constituição Federal, o Brasil passou a contar com um novo olhar sobre 0 atendimento à saúde de seus cidadãos. Considerada como um direito social, cuja responsabilidade formal é do Estado ${ }^{11}$, a saúde passou de uma concepção sabidamente excludente, centralizadora, medicalizada ehospital ocêntrica para a idéia de aten dimento integral, voltado especialmente para a preven ção e para a promoção de saúde, descentralização políticoadministrativa e de participação da sociedade.

Tal concepção não nasce direta e exclusivamente da Constituição Federal de 1988, no entanto. 0 texto referenteà saúde da própria $\mathrm{C}$ arta $M$ agna é resultado de um longo processo anterior, gestado desde a década de 70 do século XX, 
por parte de sanitaristas, acadêmicos e líderes populares, sindicais e políticos, em um cenário de busca por abertura política e de esgotamento do sistema de saúde até então vi gente, momento em que se propiciou a intensificação de movimentos sociais e a conseqüente discussão sobre o futuro do sistema de saúde. Àquela época, deuse o surgimento do chamado Movimento Sanitário, a partir de discussões sobre as políticas de saúde feitas no âmbito acadêmico ${ }^{12}$.

Tal movimento cresceu e legitimou-se pelos movimentos populares e pela atuação de parlamentares e de instituições de saúde, assim como teve grande influência sobre al guns eventos, tais como a apresentação de uma proposta de reorganização do sistema de saúde existente, a qual contemplava conceitos como universalização, integralidade e participação social; e sobre a formulação do Plano Conasp (Plano de Reorientação da Assistência à Saúde) , no âmbito da Previdência Social, o qual incorporava algumas propostas do M ovimento pela Reforma Sanitária, e que se efetivou através das Ações Integradas em Saúde, estas sendo a primeira experiência de um sistema de saúde mais integrado e articulado, e tornando-se a base para a implantação do SistemaUnificado e Descentralizado deSaúde(SUDS). Além disso, as AIS propiciaram o surgimento das Comissões Interinstitucionais de Saúde (CIS), chão para os futuros Conselhos de Saúde) ${ }^{12}$.

Posteriormente, em função da elaboração da nova Constituição, a qual dependeria de uma Assembléia N acional Constituinte, convocou-se a 8a Conferência Nacional de Saúde, em 1986, para discutir uma nova proposta da estrutura e da política do setor. Com a participação de mais de quatro mil pessoas, entre usuários do sistema, profissionais de saúde, políticos e lideranças, refletiu um processo de discussão iniciado em níveis municipais e estaduais, cujos temas de trabalho foram a saúde como direito, a reformulação do sistema nacional de saúde e financiamento setorial. Conforme seu Relatório Final, a saúde ficou entendida como resultante defatores como alimentação, habitação, educação, renda, meio ambiente, trabalho, transporte, emprego, lazer, liberdade de acesso e posse da terra e acesso a serviços de saúde ${ }^{13}$. Compreendendo a saúde por meio deste amplo conceito, princípios como universalidade, igualdade, intersetorialidade e racionalidade foram colocados em pauta.

E, enfim, em 1988, a Constituição Federal incluiu em uma seção sobre saúde alguns concei-

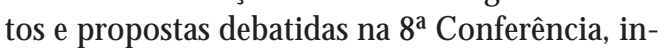
corporando, desta forma, propostas surgidas pelo M ovimento da Reforma Sanitária. Visando o cumprimento da Constituição, foi editada, em 1990, a Lei Orgânica da Saúde (LOS), formada pelas Leis Federais 8080/90 e 8142/90, as quais instituem edispõem sobre o funcionamento, organização e características do SUS. Através da Constituição e, posteriormente, da LOS, definiuse que o SU S seria regido por determinados princípios e diretrizes, e propunha-se, naquela legislação, a passagem do então modelo vigente para uma forma voltada à prevenção e promoção da saúde $\mathrm{e}^{14,15}$.

A mudança do modelo de atenção vem se desenvolvendo desde o início da década de 90 do século XX, principalmentea partir de 1993-1994, quando foram desencadeados os processos de municipalização e de implementação da estratégia de Saúde da Família ${ }^{16}$, adotada com a intenção de atender a todos os princípios legais do SUS, especialmenteos de universalidade deacesso, de integralidade da assistência à saúde e de resolutividade, englobando paulatinamentetoda a rede de serviços básicos, através da ampliação e qualificação da atenção primária em saúde.

É preciso, ainda, reforçar que o Sistema Ú nico de Saúde, embora tenha sido explicitado em sua formalização inicial pela Constituição Federal de 1988 e, posteriormente, operacionalizado por meio de legislação específica, tais como a Lei Orgânica de Saúde e pelas N ormas de O peracionalização Básicas e de Atenção à Saúde (NOBs e NOAS), não é um modelo simples e estanque. 0 SU S é um processo e, como tal, é algo em constante construção, na busca por seu próprio aperfeiçoamento, objetivos eideal.

\section{Estratégia de saúde da família}

Formada a partir de dois programas elaborados pelo M inistério da Saúde- aquelea partir do qual foi nomeado, com início em 1994/5, e o Programa de Agentes Comunitários de Saúde (PACS), iniciado em 1991 e uma espécie de precursor do Programa de Saúde da Família (PSF), a estratégia de Saúde da Família deixou de ser vista como um simples programa e passou a ser considerada como reorientadora e estruturante da organização do SUS a partir de 1997, através da Portaria 1886/GM / M S$^{17}$.

Faz-se salutar, para melhor compreensão deste trabalho, tornar claro que para os fins deste, as nomenclaturas Programa de Saúde da Família (PSF) e Estratégia de Saú de da Família são utilizadas para descrever o mesmo fenômeno. 
Esta dualidade de termos deve-se ao próprio uso dos mesmos por parte do M inistério da Saúde e das Secretarias Estaduais e M unicipais de Saúde.

A oficialização do PSF, enquanto simples programa de saúde, ocorreu em 1994, após um processo dediscussão iniciado em dezembro de1993, em Brasília. 0 que defato houve foi a institucionalização, por parte do M inistério da Saúde, das experiências de práticas em saúde com agentes comunitários, as quais já vinham sendo desenvolvidas de forma isolada em diversas regiões do país, especialmente no Ceará, onde foram transformadas em uma política estadual. 0 M S percebeu, a partir da experiência acumulada neste estado, que os agentes comunitários de saúde poderiam ser peça importante para a organização da atenção básica nos municípios ${ }^{18}$, entendendo-se atenção básica como o conjunto de ações individuais e coletivas, situadas em um nível de baixa complexidade, voltadas para a promoção da saúde, a prevenção de doenças e agravos, o tratamento e a reabilitação ${ }^{19}$.

Em sua concepção inicial, o principal propósito do PSF era tornar-se a porta de entrada do usuário ao SU S e ampliar o acesso da população aos serviços de saúde, de forma hierarquizada, através da atenção básica. No entanto, a atenção básica à saúde não pode ser enfocada apenas como uma mera porta de entrada. Ela deve resolver de 80 a $85 \%$ da demanda de saúde ${ }^{20}$ e, desta forma, exige um investimento estratégico, equea capacidade instal ada seja levada para perto da população. Ela deve fixar equipes, para produzirem vínculo, acolhimento e resolução dos problemas relacionados à saúde.

Assim sendo, transformar o programa em uma estratégia de organização foi um avanço para a gestão do SUS, uma vez que se busca não apenas 0 acesso e sua ampliação, mas também a reorganização da prática da atenção à saúde em novas bases, a substituição do modelo então vigente, levando a saúde para mais perto das famílias e melhorando-se a qualidade de vida dos cidadãos brasileiros ${ }^{19}$.

Esta mudança de modelo possibilita a integração e a organização das atividades em um território definido, com o propósito de favorecer 0 enfrentamento dos problemas identificados e implica necessariamente a articulação da aten ção básica com a média e a al ta complexidade, envolvendo a integração de políticas estratégicas desaú$d^{21}{ }^{21}$ além de envolver diversos atores, compreendendo-os como pessoas e instituições, a saber, os usuários do sistema, o gestor de saúde, a equipe de saúde da família e as lideranças comunitárias.
A implantação do PSF depende, antes detudo, de decisão política da administração municipal, que deve submeter essa proposta ao Conselho Municipal de Saúde e discutir o assunto com as comunidades queserão beneficiadas ${ }^{22}$, desta forma possi bilitando a participação da população e o controle social. Para tanto, é preciso que sejam promovidos debates e divulgação dos ideais do processo, com a presença e participação de representantes, lideranças e de outras entidades das comunidades.

Esteprocesso desensibilização edivulgação é considerado como uma primeira etapa de discussão dos princípios e diretrizes da estratégia de Saúde da Família esuas bases operacionais, evisa disseminar as idéias centrais da proposta. É extremamente necessário que todos os atores envolvidos (gestor, profissionais de saúde, lideranças e usuários) possam compreender que Saúde da Família é uma proposta com potencial para reordenar a assistência básica em saúde, de acordo com as diretrizes e princípios do SUS.

0 trabalho desensibilização e divulgação deve envolver clareza na definição do público a ser atingido e transparência na mensagem veiculada. Para tanto, podem ser programadas reuniões diversas, com o objetivo de serem articuladas alianças e de se criar familiaridade com a proposta, características necessárias ao desenvolvimento da estratégia.

Neste trabalho, devem ser enfatizados alguns aspectos como a missão do PSF e a comunicação, constituída por vários e diferentes canais de informação e de mobilização, para com isso disseminar a proposta, divulgar experiências bem-sucedidas e identificar possíveis aliados e instituições formadoras de profissionais para o sistema.

Para que a implantação do programa seja efetivada, o Ministério da Saúde, bem como as Secretarias Estaduais de Saúde devem fornecer apoio técnico e financeiro para a elaboração do projeto e paraa própria implantação, a qual passa por diversas outras etapas.

Priorizando a vigilância em saúde, cuja intenção é englobar ações de promoção, proteção e recuperação da saúde familiar de todas as pessoas, sadias ou doentes, de forma integral e contínua, a estratégia incorpora e reafirma os princípios básicos do SUS e centraliza seus esforços nas U nidades de Saúde da Família, trabalhando com base em princípios próprios, a saber: integralidade (atenção integral aos indivíduos e famílias, em todos os níveis de complexidade, de acordo com cada caso), hierarquização (o aces- 
so ao sistema deve ser feito sempre a partir da atenção básica e dela seguir para os níveis maiores de complexidade), territorialidade e adscrição da clientela (a unidade trabalha com território definido e a população nele inserida deve ser cadastrada e acompanhada) e equipe multiprofissional ${ }^{19}$.

Visualizam- $\mathrm{se}^{22}$ três características fundamentais da estratégia de Saúde da Família: em primeiro lugar, a ênfase na territorialização e na adscrição da clientela, responsabilizando cada equipe pelo cadastramento e acompanhamento das famílias do território deabrangência. Segundo, ela tem caráter substitutivo, através de suas unidades, uma vez que não constitui uma nova estrutura de serviços (excetuando-se as áreas anteriormente desprovidas de), mas sim substitui as práticas convencionais de assistência por um novo processo de trabalho, cujo eixo está centrado na vigilância à saúde e na participação da comunidadee, por fim, ela faz parte orgânica do SUS, dentro do princípio da integralidade e da hierarquização. Por isso, deve estar vinculada à rede de serviços, de forma a garantir atenção integral aos indivíduos eàs famílias, em todos os níveis de complexidade, sempre que necessário.

De acordo com as Portarias 1186/GM /M S S17 e 157/G M / M S ${ }^{23}$, recomenda-se que cada equipe de Saúde da Família seja responsável por, no máximo, 4.500 pessoas. Desta forma, a Unidade de Saúde pode ser composta por uma ou mais equipes, dependendo da concentração defamílias residentes no território ${ }^{13}$.

Cada equipe de Saúde da Família (SF) écapacitada para conhecer a realidade das famílias pelas quais é responsável, por meio de cadastramento e diagnóstico de suas características sociais, demográficas e epidemiológicas; identificar os principais problemas de saúde e situações de risco aos quais a população que ela atende está exposta; elaborar, com a participação da comunidade, um plano local para enfrentar os determinantes do processo saúde/doença; prestar assistência integral, respondendo deforma contínua e racionalizada à demanda, organizada ou espontânea, na Unidade, na comunidade, no domicílio e no acompanhamento ao atendimento nos serviços de referência ambulatorial ou hospitalar e desenvolver ações educativas e intersetoriais para enfrentar os problemas de saúde identificados ${ }^{19}$.

A equipe de SF é composta, no mínimo, por um médico preferencialmentecom formação específica, um enfermeiro, um auxiliar de enfermagem e de quatro a seis agentes comunitários de saúde. Outros profissionais têm complemen- tado as equipes básicas, como os cirurgiões-dentistas, atendentes de consultório dentário etécnicos de higiene oral. Ainda outros podem ser incorporados à equipe ou mesmo formar equipes de apoio, como farmacêuticos, fonoaudiólogos e assistentes sociais.

Cada profissional da equipebásica deSF possui uma determinada atribuição. No entanto, cabe a todos fomentar e desenvolver, conjuntamente, ações preventivas e de promoção da qualidade de vida da comunidade, além de ações de recuperação e de reabilitação da saúde, tanto na unidade de saúde quanto nos municípios, aliando, desta forma, a atuação clínica etécnica à prática da saúde coletiva.

Além das atribuições específicas, os profissionais da equipe têm diversas responsabilidades em comum, como conhecer a realidade das famílias pelas quais são responsáveis, identificar seus problemas desaúdeesituações de risco mais comuns, e construir conjuntamente um plano local para o enfrentamento dos mesmos, discutindo com a comunidade conceitos decidadania, de direitos à saúde e suas bases legais ${ }^{24}$.

Dentre os profissionais da equipe, surgecomo ator de grande importância o agente comunitário de saúde $(A C S)$, o qual faz a ligação entre a comunidade e o serviço de saúde, visitando cada família pelo menos uma vez por mês, realizando o mapeamento de sua área, o cadastramento das famílias e estimulando a comunidade à participação social. O ACS é, ao mesmo tempo, membro da equipe desaú de eda própria comunidade onde atua, salientando-se que ele deve ser morador desta comunidade há pelo menos dois anos, de forma que possa conhecer as pessoas e a realidade da comunidade e ser conhecido por elas ${ }^{25}$. Suas atividades são extensas, englobando desde a identificação de indivíduos e famílias expostos a situações de risco, até o desenvolvimento de ações de edu cação e vi gilância à saúde, mobilização comunitária e identificação de parceiros e recursos existentes na comunidade que possam ser potencializados pela equipe ${ }^{24}$.

Cabe explicitar que as equipes atuam com outros setores desaúde, como os serviços de saúde ambulatoriais, hospitalares e de vigilância sanitária eepidemiológica, além de outras áreas relacionadas à prevenção, promoção e recuperação da saúde, como educação, saneamento, meio ambiente, dentre outros, configurando, desta forma, preocupação com o princípio de intersetorialidade, preconizado pela Lei Orgânica da Saúde ${ }^{14}$.

Passados cerca de dez anos da implantação 
do PSF, posteriormente transformado em estratégia, são mais de 60 milhões de pessoas acompanhadas por quase 19.200 equipes, na maior partedosmunicípios brasileiros. Entretanto, ainda há desafios, dentre os quais a sua própria qualificação e a necessidade de se avançar na integralidade e na resolutividade da atenção em saúde.

Além das citadas acima, algumas dificuldades têm sido encontradas para a implantação desta proposta nos municípios, relacionadas a apoio técnico das secretarias de saúde, em nível municipal e/ou estadual: integração com a rede local de saúde e/ou com os com os demais programas de saúde; planejamento e monitoramento das ações, alcance das metas previstas, impacto das ações, carências de rede física, insumos, medicamentos ou equipamentos, entre outros.

\section{Análise da confiança nas relações entre os atores do PSF}

Entre os principais atores que participam ativamente do PSF, destacam-se os gestores de saúde pública, os integrantes das equipes de saúde da família, as lideranças comunitárias e os próprios usuários do SUS. Entre todos eles, estabelecemse relações que possuem diferentes características, as quais influenciam diretamente na construção e manutenção da confiança.

Como recurso didático para facilitar a análise da importância da confiança nas relações entre tais atores, elas são aqui estudadas dividindo-secada teia de relacionamentos de acordo com suas próprias especificidades, ainda que todos estejam ligados, conforme o que segue:

A confiança entre os membros da equipeéimportante, principalmente, devido ao caráter multiprofissional eà granderesponsabilidade do tipo de trabalho desenvolvido, o qual envolve diretamente a saúde de cidadãos brasileiros, em nível individual e coletivo.

A transparência entre os integrantes da equipe, ou seja, uma atitude por parte de todos os membros do time em agirem de modo que as informações disponíveis sejam compartilhadas, é um dos pontos-chave para evitar-se uma possível quebra da confiança. Desta forma, desejase que não ocorra a sonegação proposital de informações, o chamado 'segredo sistemático', uma potencial ameaça para as relações de confiança ${ }^{6}$.

Essa falta de confiança entre os membros poderia trazer conflitos durante o trabalho e, conseqüentemente, chegar a comprometer não apenas de forma pontual, mas todo o relacionamento da equipe e o êxito do programa, já que a quebra da confiança pode trazer conseqüências para todo o relacionamento estabelecido entre os indivíduos ${ }^{1}$ e, conseqüentemente, entre os diversos atores sociais, prejudicando o resultado do trabalho desenvolvido entre as partes.

Deve ser salientada a importância da cooperação em um trabalho como o da equipe de saúde da família, cooperação esta que pode ser potencializada e ocorrer em bases mais sólidas caso as relações entre os membros sejam perpassadas pela confiança. A falta de confiança dos ACS na equipe, por exemplo, pode dificultar a utilização da equipe por parte da população, assim como a confiança dos técnicos no ACS pode facilitar a ação de saúde, com base no seu diagnóstico e nas suas informações.

A confiança da equipe nas lideranças comunitárias, embora não possa ser considerada fundamental para o desenrolar das atividades, pode vir a ser um facilitador no processo, principalmente no seu início, quando as equipes necessitam de informações sobre as comunidades a serem beneficiadas pelo Programa. Esta confiança podeser influenciada pelas experiências anteriores einformações prévias (familiaridade) do ACS sobre estas lideranças. Além disso, por meio da reciprocidade, 0 ato de confiar nas lideranças pode estimular que estas também confiem na equipe de saúde da família.

Da mesma forma, a confiança das lideranças comunitárias na equipe tem grande relevância, principalmente durante as etapas iniciais do trabalho junto à comunidade, para que ocorra o compartilhamento das informações entreos dois atores sociais. Pelo fato de o ACS já ser da comunidade e, em geral, conhecido destas lideranças, o relacionamento prévio com ele podeinfluenciar diretamente o relacionamento com a equipe. É importante que a confiança perpasse as relações entre a equipe e as lideranças, mesmo em etapas posteriores de implantação, para que 0 trabal ho deste time ganhe o reconhecimento e a legitimação destas lideranças, em constante diálogo com o gestor e o poder público. Também pode ser facilitada a mobilização e a sensibilização da comunidade quando as lideranças confiam na equipe.

A confiança da equipe no gestor de saúde tem efeitos significativos no resultado do trabalho. Se os membros da equipe de saúde não confiam no gestor, enão acreditam que el eirá utilizar adequadamente as informações coletadas por eles para a promoção da saúde pública, a equipe pode 
passar a não realizar seu trabalho com o mesmo zelo, já que não perceberia o reconhecimento esperado, colocando em risco a eficiência do siste$\mathrm{ma}^{26}$, já que o zelo no trabalho se mostra indispensável. Também nesta relação, a reciprocidade se mostra relevante.

Por outro lado, na medida em que o gestor confia em uma equipede saúdeda família, eleterá maior propensão a utilizar as informações por ela coletadas para tomadas de decisão políticoadministrativas e para a elaboração das políticas de saúde do município.

É importante que a confiança perpasse as relações entre a equipe e os usuários. Primeiramente, um comportamento por parte da equipe, 0 qual demonstrequeesta confia nosusuários, pode ser servir de base para que estes, reciprocamente, também confiem nela. Além disso, éfundamental que a equipe confie nos cidadãos, já que são eles que fornecem as informações-base para os diagnósticos de cada família e suas ações posteriores.

Tão ou mais importante que a confiança da equipe nos usuários é o oposto: a confiança destes nos membros integrantes da equipe de Saúde da Família. 0 usuário éo pilar de sustentação de toda a Estratégia de Saúde da Família.

Sem que o usuário confie na equipe, todo o processo é dificultado. É ele que deve abrir as portas de sua casa para que os técnicos possam realizar seu trabalho, bem como Ihes fornecer informações sobre seus hábitos, costumes e necessidades de saúde. Deve-se levar em conta que estes dados fornecidos são, muitas vezes, confidenciais e até mesmo constrangedores e, assim, fica clara a necessidade de queestes usuários confiem na equipe para que possam ser tão sinceros quanto for possível.

Além disso, as pessoas, ao aceitarem o tratamento das equipes de saúde da família, confiam sua saúde à ela e, desta forma, o sucesso do tratamento depende em grande parte da sua confiança na capacidade técnica da equipe, no sentido de que os diagnósticos e as prescrições sugeridas sejam seguidas. Entretanto, esta confiança se caracteriza como a única alternativa para alguns pacientesem determinados momentos, jáqueeles não possuem outras opções para dar conta das enfermidades enfrentadas.

Para que os usuários confiem na equipe, o papel do ACS ganha mais uma vez uma importância significativa. Visto que ostécnicossão usualmente desconhecidos dos pacientes, éjustamente o papel desempenhado por esse agente comunitário que, como elo de ligação, pode facilitar a construção da confiança.
Como o ACS tem que morar há pelo menos dois anos na comunidade ${ }^{25}$, isto pode facilitar bastantea construção da confiança com elementos da familiaridade (através do conhecimento e informações sobre este membro da comunidade) e realidade coletiva cognitiva (se as demais pessoas o acham confiável, isso facilitará com que o usuário também o consideremerecedor de sua confiança) - daí percebe-se que éinteressante que o ACS tenha uma "boa reputação" na comunidade.

Outro ponto crucial no relacionamento entre os membros da equipe e os usuários é que todos os profissionais de saúde integrantes do time, em especial o ACS, tenham um comportamento que inspiree reiterea confiança depositada neles pelos pacientes. A ética no manuseio das informações coletadas mostra-se um facilitador do processo, se percebida desta forma pelos usuários. Nesta questão, para a construção da confiança entre os pacientes e a equipe, além do comportamento, mesclam-se elementos como a identificação de valoreseboas razões, principalmente com o ACS, quejá é conhecido da comunidade.

De forma análoga, os usuários terão mais propensão a confiar na equipe sabendo que 0 ACS também confia, ou ao menos parece confiar nela. Ou seja, para que os usuários se sintam mais seguros para permitir a entrada da equipe em suas casas e para fornecer-Ihe as informações solicitadas, o ACS atua como peça-chave, uma vez que é o único indivíduo já conhecido por eles. Q uanto mais confiarem nele, maior éa tendência de que confiem na equipe da qual ele faz parte.

Expectativas excessivas por parte dos usuários quanto ao poder de ação das equipes podem ser frustradas e representarem um risco paratoda a relação com estas, e também para o sucesso do programa. Logo, é salutar que seja deixado claro, desde o início, até onde vai o limite de cada um dos envolvidos no programa, agindo-secom total transparência.

No relacionamento entre os usuários e o gestor de saúde, os primeiros depositam no último uma série de expectativas quanto à solução de diversas carências. A confiança do usuário no gestor de saúde está atrelada a e é influenciada, em grande parte, pelas experiências prévias vivenciadas com este gestor, bem como com as gestões anteriores e com o poder público de uma maneira geral. Ou seja, a confiança depositada no gestor de saúde éfortemente influenciada pela confiança no Estado, no poder público. A identificação de valores neste gestor, bem como o fato 
dele ser considerado confiável pelo resto da população (realidade coletiva cognitiva), pode ajudar no processo de construção da confiança nesta relação. A importância da confiança perpassar estas relações reside no fato de fazer com que a população tenha maior propensão a aceitar e reconhecer 0 trabalho da equipe de saúde.

0 trabalho de sensibilização e divulgação do PSF a ser implantado em uma comunidade, responsabilidade do gestor, também pode ajudar para que os usuários desenvolvam a confiança nele, já que esta etapa visa fornecer aos envolvidos informações sobre o programa, contribuindo com a dimensão cognitiva da confiança. Em contrapartida, quanto maior o nível de confiança depositada pelo gestor de saúde nos usuários, maior poderá ser a aceitação dos diagnósticos recebidos como fidedignos, podendo fazer com que as reivindicações comunitárias tenham mais chances de ser atendidas.

Quanto mais os usuários confiarem entre si, e na força que têm em grupo, mais aumentam as chances de mobilização popular em prol da busca pelos seus direitos e reivindicações. Os laços afetivos entre estes cidadãos, bem como a familiaridade e a identificação de valores podem vir a ser grandes facilitadores para o desenvolvimento da confiança entre eles.

Em consonância ao exposto no parágrafo anterior, na medida em que as lideranças comunitárias confiam entre si, elas podem ganhar força política para lutarem pela satisfação das necessidades e reivindicações da comunidade. Esta confiança tem como principais facilitadores a identificação de valores e as experiências anteriores vivenciadas entre elas.

A confiança dos usuários nas lideranças é importante já que estas se constituem na representação desses usuários junto ao poder público, levando suas reivindicações de maneira direta ao gestor. De forma inversa, a confiança existente entre as lideranças e os usuários se constitui em uma forma de reduzir as incertezas quanto às solicitações da comunidade e em um estímulo para a luta pelas suas próprias necessidades. A presen ça da confiança nestas relações éfortemente influenciada pelo histórico das experiências anteriores entre as partes, mas também pode sofrer interferência da afetividade existenteentreelas.

A confiança das lideranças no gestor de saúde faz com que as comentadas carências e solicitações da comunidade sejam levadas ao poder público de forma mais rápida. Em contrapartida, a confiança do gestor nas lideranças pode facilitar o apoio político ao governo. Quando este relacionamento édominado pela descrença, muitas vezes com base em experiências anteriores malsucedidas, a relação política entre os atores pode ficar fragilizada e fazer com que os interesses de ambas as partes se tornem mais difíceis de ser atingidos.

Analogamente ao caso das relações entre os membros das equipes de saúde deverem ser perpassadas pela confiança, quanto maior o seu nível entre as lideranças comunitárias, maior será a capacidade demobilização eluta pelas reivindicações dos direitos dos usuários do Sistema Ú nico de Saúde, por meio do PSF.

Com o intuito de permitir melhor compreensão e visualização da importância da confiança para as diversas relações supra analisadas, apresenta-se um quadro-síntese abaixo. As relações de confiança existentes entre os gestores de saúde não foram analisadas neste trabalho devido ao grande número de possibilidades que poderiam advir como conseqüência da divisão do poder público em três esferas de governo (federal, estadual e municipal). Desta forma, estas relações não se constituíram em parte do objetivo deste trabalho, mas podem ser analisadas através de pesquisas posteriores.

Por fim, resta uma indagação: seguindo-se os pressupostos da dimensão emocional da confiança e a 'confiança personalizada' seleção de membros para as equipes deve tentar dar preferência a profissionais que possuam uma propensão maior a confiar em terceiros (já que estas se relacionam diretamente com todos os demais atores envolvidos)? 


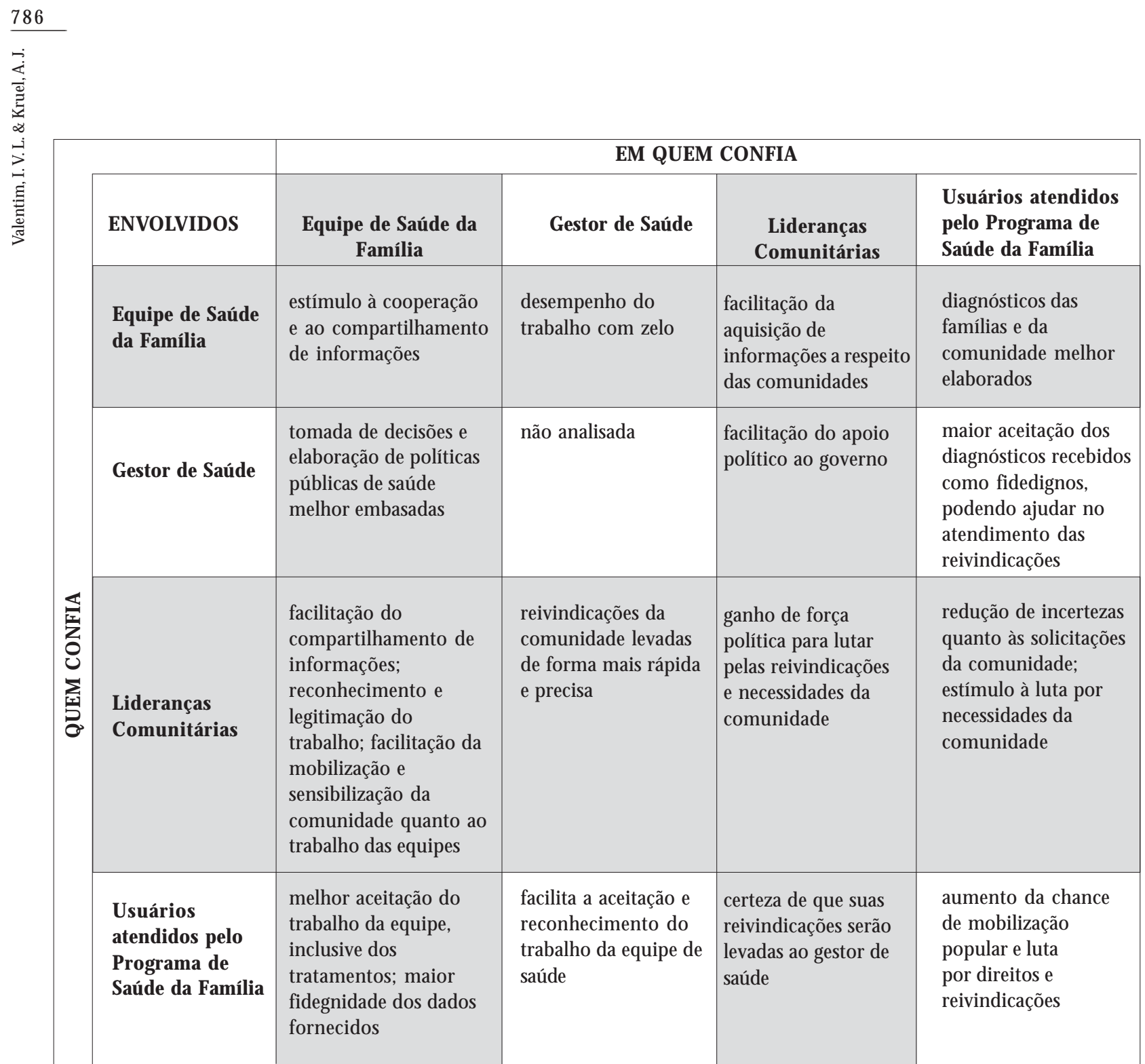

\section{Considerações finais}

A pós a análise do Programa de Saúde da Família, percebe-seque o mesmo tem um papel extremamente relevante para o êxito das políticas de saúde do governo federal, e mesmo para a proposta de reordenamento do modelo de atenção à saúde. Porém, proporcional à sua capacidade decontribuir para o Estado e para a sociedade, é sua complexidade, a qual engloba diversas teias de relacionamentos que compreendem atores sociais de diversos setores da sociedade.

Conclui-se que a confiança entre os diversos envolvidos no PSF éum item de importância ímpar para o êxito do programa. Embora sua presença seja relevante para as relações entre todos os envolvidos no programa, nota-se que a confiança dos demais atores sociais na figura do AgenteComunitário deSaúde possui um papel central no processo, já que ele é o elo de ligação entre o poder público e a comunidade, se constituindo no mais importante facilitador e potencializador das ações voltadas para os usuários do SUS.

Para trabalhos futuros, semostra interessante que sejam realizadas pesquisas de campo a fim de comprovar, empiricamente, os facilitadores e barreiras no processo de construção da confiança entre os participantes do PSF. Também surge a possibilidade de que sejam analisadas as relações existentes entre os gestores de saúde das diversas esferas de governo (federal, estadual e municipal). 


\section{Colaboradores}

IVL Valentim eAJ Kruel participaram igualmente das etapas de elaboração deste artigo.

\section{Referências}

1. Lewis $D$, Weigert A. Trust as a social reality. Social Forces 1985; 63 (4):967-985.

2. Sato CT. Gestão Baseada em Relações de Confiança. RAE - Eletrônica [periódico na Internet]. 2003 [acessado 2004 Out 01]. 2(1). Disponível em: http:/ /www.rae.com.br

3. Morrow Jr JL, Hansen MH, Pearson AW. The cognitive and affective antecedents of general trust within cooperative organizations. Journal of M anagerial Issues 2004;16(1):48.

4. Luhmann N. Trust and Power. Chichester: John Wiley and Sons; 1979.

5. M cAllister DJ. Affect and cognition-based trust as foundations for interpersonal cooperation in organizations. A cademy of M anagement Journal 1995; 38 (1):24.

6. Dejours C, Jayet C. Psicopatologia do trabalho e organização real do trabalho em uma indústria de processo: metodologia aplicada a um caso. In: Dejours C, Jayet C, organizadores. Psicodinâmica do trabalho: contribuições da Escola Dejouriana à análise da relação prazer, sofrimento e trabalho. São Paulo: Atlas; 1994. 
7. Seligson MA, Rennó LR. Mensurando confiança interpessoal: notas acerca de um conceito multidimensional. Dados [periódico na Internet]. 2000 [acessado 2004 Out 26]. 43(4). Disponível em: http:/ / www.scielo.br/scielo.php?script=sci_arttext $\& p i d=S 0011-525820000004000007 \& \ln g=e n \&$ $\mathrm{nrm}=\mathrm{iso}$

8. Goffman E. A representação do eu na vida cotidiana. Petrópolis: Editora Vozes; 2003.

9. Gambetta D. Trust: Making and Breaking Cooperative Relations. Oxford: Basil Blackwell; 1998.

10. Ruppel $\mathrm{CP}, \mathrm{Harrington} \mathrm{SJ}$. The relationship of communication, ethical work climate, and trust to commitment and innovation. Journal of Business Ethics 2000; 25:313-328.

11. Brasil. Constituição da República Federativa do Brasil. Brasília: Gráfica do Senado; 1988.

12. Oliveira AGRC, Souza ECF. A saúde no Brasil: trajetórias de uma política assistencial. In: Odontologia preventiva e social: textos selecionados. $N$ atal: EDUFRN; 1997. p. 114-25.

13. Brasil. 8a Conferência Nacional de Saúde - Relatório Final. Brasília: Ministério da Saúde; 1997.

14. Lei $n^{\circ} 8080 / 90$ de 19 de setembro de 1990. Dispõe sobre as condições para a promoção, proteção e recuperação da saúde, a organização e o funcionamento dos serviços correspondentes e dá outras providências. Diário Oficial da União, 19 set.

15. Lei $n^{\circ} 9142 / 90$ de 28 de dezembro de 1990. Dispõe sobre a participação da comunidade na gestão Sistema Ú nico de Saúde (SUS) e sobre as transferências intergovernamentais de recursos financeiros na área da saúde e dá outras providências. Diário Oficial da União, 28 dez.

16. Teixeira CF. Saúde da Família, Promoção e Vigilância: construindo a integralidade da atenção à saúde no SUS. Revista Brasileira de Saúde da Família 2004; 10-23.
17. Portaria $n^{\circ} 1.886 / \mathrm{GM} / \mathrm{MS}$ de 18 de dezembro de 1997. A prova as Normas de Diretrizes do Programa de Agentes Comunitários de Saúde e do Programa de Saúde da Família. Diário Oficial da U nião, 22 dez.

18. Andrade LOM. Sistema de Salud de Brasil - normas, gestion y financiamiento. São Paulo: Ed. Hucitec; 2002.

19. Ministério da Saúde. Portal da Saúde. [Portal na Internet] 2005. [acessado 2005 Abr 27]. Disponível em: http://portal.saude.gov.br

20. Santos NR. U m novo pacto para o SUS. In: Seminário de Experiências Internacionais em Saúde da Família - Relatório Final. Braślia: Ministério da Saúde; 2002.

21. Costa H. Editorial. Revista Brasileira de Saúde da Família. Brasília: M inistério da Saúde; 2004.

22. Bonassa EC, Campos CVA. Saúde mais perto: os programas e as formas de financiamento para os municípios. Brasília: Ministério da Saúde; 2001.

23. Portaria $n^{\circ} 157 /$ GM /MS, de 19 de fevereiro de 1998. Estabelece os critérios de distribuição e requisitos para a qualificação dos Municípios aos incentivos ao Programa de Agentes Comunitários de Saúde e ao Programa de Saúde da Família. Diário Oficial da União, 26 mar.

24. Pólo PSF. Pólo de Capacitação - Formação e Educação Permanente de Recursos Humanos para Programa Saúde da Família de Marília-SP. [Capacitação na Internet] 2005. [acessado 2005 Abr 28]. Disponível em: http://www.famema.br/saudedafamilia

25. M inistério da Saúde. Agentes em Ação. Brasília: Ministério da Saúde; 1997.

26. Dejours C. A banalização da injustiça social. Rio de Janeiro: Fundação Getúlio Vargas; 2003.

Artigo apresentado em 26/07/2005

Aprovado em 10/11/2006

Versão final apresentada em 09/11/2006 